\title{
HISTORIA "FUERA DE CONTEXTO": ARTEFACTOS DE HISTORIA ENTRE LOS COMCAAC DEL NORTE DE MÉXICO Y REGISTROS AMERINDIOS DEL CONFLICTO
}

\author{
María Isabel Martínez Ramírez ${ }^{1}$ \\ ${ }^{1}$ Instituto de Investigaciones Históricas, \\ Universidad Nacional Autónoma de México
}

El título de este artículo ${ }^{1}$ alude a uno de los problemas centrales en la obra de Marilyn Strathern. En la Frazer Lecture de 1986, titulada Out of context: the persuasive fictions of anthropology, Strathern (2014a) problematizó los sentidos otorgados a la historia de la antropología y a sus rupturas. Explicó por qué, desde la perspectiva de Bronislaw Malinowski (1922: 24-25), quien procuró "entender el punto de vista nativo [...] y la comprensión de su visión de su mundo", la apuesta de James Frazer para "dilucidar conceptos ajenos colocándolos en su propio contexto social" (Strathern 2014a: 25) resultaba ilegible. Desde la mirada malinowskiana, Frazer abordó eventos, comportamientos, dogmas y ritos "fuera de contexto" (Strathern 2014a). El motivo era que sus escritos carecían de las ficciones persuasivas utilizadas por la antropología posmoderna para formular los conceptos construidos como ajenos mediante la manipulación de conceptos propios y, así, establecer distancias entre el escritor, el lector y el objeto de estudio (Strathern 2014a) —-tales como la organización de una monografía, la existencia de la verdad, de la autoría, de la objetividad, etc. Por tanto, estar "fuera de contexto" era la posición otorgada desde una percepción antropológica particular ubicada en un proceso histórico.

En "Artefatos da historia: os eventos e a interpretação de imagens", Strathern (2014b) vuelve a este problema con el objetivo de mostrar por qué la llegada de los europeos a Nueva Guinea no debía insertarse en un "contexto social", ya que para los melanesios: "Las imágenes que contienen en sí mismas tanto el tiempo pasado como el futuro [...] incorporan la historia" (Strathern 2014b: 211). Paralela a la lectura de las propuestas de 
esta antropóloga, mi comprensión de los vínculos entre contexto e historia es resultado de las relaciones de coproducción de conocimiento generadas con los rarámuri que residen en la Sierra Tarahumara de Chihuahua, México (ver Martínez Ramírez 2020) y con algunas mujeres tejedoras comcaac o seris de las costas de Sonora, México (Martínez Ramírez 2016a y 2016b).

En este tenor, el objetivo de este artículo es examinar las fricciones involucradas en el desencuentro entre: 1) la obligación de construir un marco de referencia capaz de definir todo aquello que encuadra como meras ilustraciones o ejemplares de sí mismo y que, en última instancia, ha llegado a ser nuestro objeto de estudio, reduciendo nuestra labor a una mera reconstrucción e interpretación de contextos. Por ejemplo, el contexto social entendido como la sociedad, el contexto histórico como la historia o el contexto cultural como la cultura (Strathern 2014b: 225). Y 2) las teorías y las prácticas de los comcaac, bajo las cuales determinados artefactos y performances autocontienen un contexto que precede al cuadro de referencia de nuestras narrativas académicas (Strathern 2014b: 219). La finalidad es evidenciar los efectos analíticos de tal desencuentro mediante el examen de la noción de registro amerindio del conflicto, y contribuir a un debate más amplio sobre las relaciones entre la escritura de la historia indígena contemporánea en México y la construcción de contextos que toman como marco de referencia al Estado nación moderno. En este camino, sigo de cerca la discusión planteada por Federico Navarrete Linares $(2019,2018$, 2016) a través del concepto de cosmohistoria, así como los ensayos críticos al nacionalismo mexicano elaborados por la lingüista mixe Yásnaya Aguilar Gil (2017); ambos ligados a la discusión del racismo.

Manuela Carneiro da Cunha (1992: 21-22) señaló que en Brasil: "La historia de los indios no se subsume en la historia indigenista". Para el caso mexicano intuyo que sucede lo mismo y que "aún queda por hacer una historia propiamente indígena"; ya que, en gran medida, los textos dedicados al estudio de la historia indígena contemporánea, incluyendo aquellos preocupados por atender el punto de vista de los nativos, siguen las premisas de la historia cosmopolita promovida por Kant (1987 [1784]). Bajo su sombra, el tiempo es lineal y progresivo, es posible diferenciar claramente entre el presente y el pasado, y los estudiosos deben distinguir adecuadamente los eventos propiamente históricos de aquellos que no son "racionales". Este tipo de historia ha sido constitutiva de los programas de cambio cultural ejecutados por el Estado mexicano, particularmente del proyecto de mestizaje comandado por la antropología y la política indigenista durante el siglo XX y que, evidentemente, está articulado con el racismo del cual hablé antes (Navarrete Linares 2015). 
En esta mezcla de política, historia y antropología, por ejemplo, se ha aseverado que "la autoctonía no antecede a las relaciones sociales ni a la historia, sino que es su resultado" (López Caballero 2017: 31, 60). Desde esta postura, los regímenes de alteridad amerindios que hemos conocido y documentado durante los siglos XX y XXI son producto de los Estados nación y son "consumidos" por aquellos a quienes está destinado. Algunos autores defensores de esta posición han intentado resolver "el problema ético" que implica este tipo de reflexiones, argumentando que no es de su interés invalidar dichos regímenes de alteridad y, con ellos, las demandas políticas y territoriales de los pueblos con los que trabajan en el presente, mucho menos discutir "la auténticidad étnica" de nadie, sino demostrar que la categoría de indígena es un campo permanente de negociación y disputa comandado por el Estado nación (López Caballero y Acevedo-Rodrigo 2018: 5-6). Abrir un espacio para una historia propiamente indígena podría enriquecer de manera crítica estos planteamientos y esta discusión.

Para lograr el objetivo planteado, primero presento un recuento etnográfico de la experiencia de co-creación con algunas tejedoras comcaac con el fin de evidenciar la tensión entre, por un lado, la construcción de un contexto que toma como referente al Estado mexicano y, por otro, las teorías y las prácticas vinculadas con la manufactura de la cestería y de los diseños tejidos en ella. Posteriormente, muestro cómo la cestería seri podría ser análoga a los artefactos de historia descritos por Strathern. La propuesta es explorar la paradoja que surge al sustituir nuestros marcos de referencia por un contexto nativo que ha sido reconstruido en el gabinete. Por último, a través de la noción de registros amerindios del conflicto, exploro las hipótesis y las consecuencias de reconocer que dichos registros incorporan la historia y con ella sus contextos de elucidación. 


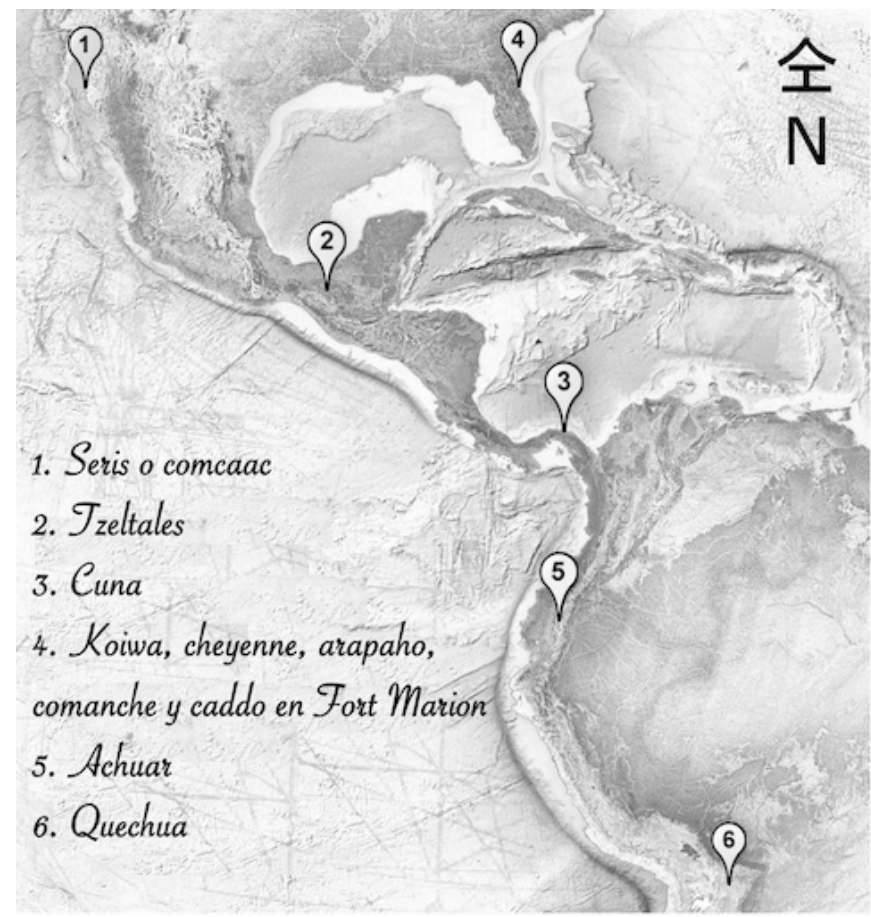

\section{La paradoja de los contextos²}

Entre 2013 y 2014 pasé un par de temporadas de campo entre la población comcaac o seri que reside en El Desemboque del Río San Ignacio o de los Seris, municipio de Pitiquito, Sonora, en el norte de México. ${ }^{3}$ El Desemboque cuenta con una escuela de preescolar, una primaria y recientemente con una preparatoria (Carolyn O'Meara, comunicación personal junio de 2020), así como con una clínica del Sistema de Salud donde un médico y un dentista suelen atender cada dos semanas; cuenta también con suministro de agua potable entubada a partir de un pozo y con luz eléctrica aproximadamente desde el año 2000. Se usan estufas de gas, hay un teléfono e internet satelital. Los comcaac son aproximadamente 900 personas hablantes de seri o Cimque Iitom, de español y en algunos casos de inglés (O'Meara 2010: 15, 19). 
Durante el siglo XX el estilo de vida de esta nación, como ellos se autodefinen, fundamentado en la caza, la pesca y la recolección, la ocupación del territorio en campamentos (Bowen 1983, Cuéllar 1980, Felger \& Moser 1985, Griffen 1955), y una organización en unidades sociales diferenciadas —bandas o tribus hablantes de distintos dialectos (O'Meara 2010)— cambió radicalmente. Algunos investigadores han explicado este proceso como la integración y la dependencia a una economía monetaria y capitalista, seguido por campañas de evangelización que iniciaron en la década de 1960, como mudanzas radicales e impuestas por políticas de despojo y exterminio. Otros lo han entendido como el cambio gradual hacia un estilo de vida sedentario, motivado particularmente por el interés de los seris en el acceso a bienes de servicio como el agua, el desarrollo de la pesca comercial y la venta de artesanías (Nolasco 1967, Robledo Hernández 1981, Pérez Ruíz 1993, Spicer 1997 [1962]: 117, Rentería 2007: 20). A pesar de que cada perspectiva ofrece un retrato relativamente diferencial de esta nación, en esta literatura la existencia actual de los seris se entiende como un conjunto de actos utilitarios de sobrevivencia o de resistencia articulados con el sistema económico y social promovido por el Estado mexicano o, bien, como el survival de un pasado prehispánico (Gutiérrez 1999, Aguilar Zeleny 2013).

En aquel momento realizaba una estancia postdoctoral en historia del arte y mis objetivos de investigación consistían en actualizar el registro etnográfico de la cestería de rollo manufacturada por las mujeres seris y en poner en marcha una metodología de coproducción de conocimiento con estas tejedoras. La cestería seri, una de las principales fuentes de ingresos económicos en El Desemboque, es elaborada con torote (Jatropha cuneata) o haat y es tejida mediante una técnica de enroscamiento simple de anillos cerrados o abiertos que recubre un fajo fundacional en sentido antihorario. El rollo se perfora desde el exterior de la pieza generando el mismo diseño en ambas caras con una calidad similar en el tejido.

Durante el desarrollo de esta pesquisa observé la fricción que generaba el desencuentro entre: 1) la obligación de construir un contexto histórico para ubicar los procesos de cambio y de permanencia de dicha cestería y 2) las relaciones involucradas en la creación de estos artefactos y que simultáneamente los constituían. Dicha fricción fue producto de las relaciones de coproducción de conocimiento mediante las cuales las mujeres seris y quien suscribe este artículo diseñamos la pregunta, la ruta crítica, las herramientas de construcción de la información, así como las premisas y las categorías analíticas. Para ejemplificar tal desencuentro, retomo los problemas planteados por los diseños tejidos en esta cestería. 
Esta cestería ha sido elaborada exclusivamente para su venta desde la década de 1960 del siglo XX (Bowen 1983: 239) y el primer registro fotográfico de una canasta con diseños data de principios del siglo pasado (García y Alva 1905: s.p). Por ello, la literatura etnográfica e histórica se concentró en discernir el origen y el desarrollo de los diseños a partir de la mercantilización de la cestería, principalmente en los circuitos comerciales del Native American Art en el sur de los Estados Unidos, y en explicar que la variación individual de su producción y denominación era descriptiva, inconsistente y carente de significado (Bowen 1973 y 1983, Cuéllar 1980, Felger \& Moser 1985, Griffen 1955, Johnson 1959, Moser 1973, Schindler 1981, Smith 1959).

De esa manera, el origen y el desarrollo de los diseños explicaba por qué estos carecían de un valor simbólico, ceremonial, mágico y chamánico y, en consecuencia, daban cuenta de su reducción a un objeto ornamental y utilitario. Estos diseños eran comprendidos como la expresión del desgaste o de la corrupción cultural provocadas por el contacto con el capitalismo y la globalización y, simultáneamente, como la sobrevivencia de un pasado glorioso. Desde mi lectura, estas interpretaciones eran una metonimia de los relatos antropológicos dedicados a la historia de esta nación. Pues tanto los diseños tejidos en la cestería como los seris eran tendencialmente descritos como carentes de un contenido cultural auténtico que, ya sea por pérdida, desgaste o vaciamiento, han enfrentado a esta nación a la necesidad de "inventar" una tradición ficticia (en el sentido otorgado por Eric J. Hobsbawn 1983), pero útil para obtener un lugar como indígenas o indios en el marco de referencia de esta narrativa, es decir, el Estado nación.

Tal como afirmaba Strathern, estas narrativas expresan cómo nuestra labor académica ha quedado reducida a la reconstrucción y a la dilucidación del contexto. En este caso, el Estado nacional y su historia son el marco de referencia que daría cuenta, como un ejemplo de sí mismo, de los diseños de la cestería, de la historia de los seris y de los seris. Aún así y sin sospecha de duda, el genocidio acometido a finales del siglo XIX, el etnocidio que le ha sucedido durante los siglos XX y XXI (lingüístico ${ }^{4}$ mediante la falta de acceso a servicios básicos y a los derechos humanos), la reducción y la explotación territorial que los seris han sufrido son fundamentales para entender la situación actual de esta nación (Spicer 1997 [1962]: 114, Ramírez Zavala 2018: 15-16).

Por tanto, esta violencia es una premisa para reconsiderar la pertinencia, como antropólogos o historiadores, de nuestras ideas sobre los survival, y las elecciones de los seris, y de otros pueblos, estimuladas en un supuesto interés utilitario para autoinventarse una identidad. Más aún, son una oportunidad 
para contemplar el carácter infernal que estas elecciones han tenido para los seris, en los términos propuestos por Isabelle Stengers (2013). Finalmente, son una posibilidad para advertir, tal como señaló Manuela Carneiro da Cunha (2014 [2009]: 313) para otros casos en Amazonía, que: "La política académica y la política étnica caminan en direcciones contrarias", y para reconocer y elegir nuestro papel en cada una de estas políticas.

Insatisfecha con las explicaciones contextuales de un Estado nación que daban cuenta de la historia de los seris y, particularmente estimulada por los procesos de coproducción de conocimiento con las tejedoras de El Desemboque, enfoqué mi reflexión en las relaciones involucradas en la creación de la cestería que simultáneamente la constituían (Leach 2002, Henare, Holbraad \& Wastell 2006).

Desde esta óptica, los diseños en la cestería, tanto como las canastas, fungían como técnicas de vinculación social para las mujeres seris. En el proceso de la manufactura se condensaban algunas formas de producción social o de reproducción del colectivo, tales como la distinción individual, la variabilidad familiar, la creación de consensos familiares, la intensificación de las relaciones con los no seris y la producción de la "tradición" entendida como los conocimientos especializados en el canto o en la danza, las experiencias que algunas personas habían atestiguado y los aprendizajes heredados por sus padres. A continuación ofrezco un ejemplo de estas articulaciones.

La primera técnica de investigación en trabajo de campo que utilicé para conocer estos diseños fue la recopilación de léxico en Cimque Iitom. Para ello, conformé una base de datos representativa de los canastos y de los diseños tejidos durante la segunda mitad del siglo XX con fotografías de la Colección Etnográfica del Museo Nacional de Antropología ${ }^{5}$ y con reproducciones de las imágenes del artículo de Edward Moser (1973). ${ }^{6}$ El resultado corroboró, tal como otros autores habían documentado, una variación que imposibilitaba sistematizar la información bajo nuestros marcos contextuales.

En el proceso de coproducción de esta investigación, las tejedoras seris organizaron reuniones familiares en las que, a partir de las cualidades gráficas de los diseños, reflexionaron colectivamente sobre aquella variación. Con base en estas condiciones de transmisión del conocimiento, estas mujeres me enseñaron que el consenso familiar funcionaba como el vínculo entre la producción de conocimiento individual y aquello que denominaban "tradición". Un ejemplo de esto es cómo las tejedoras seris percibían la experiencia creativa durante la elaboración de los diseños. Por una parte, dicha experiencia era producto de la copia y de la incorporación de motivos de otras personas y de otras tradiciones gráficas; por otra, era entendida 
como un proceso inevitable de innovación individual. Este fue el caso de una mujer que enseñaba a su hija cómo tejer el diseño de la mariposa (seenel). Esta última alargaba las alas y modificaba las antenas para generar su propio estilo. Al mostrarme su canasto, esta aprendiz, recurriendo a la experiencia donde la variación era algo natural que se incorporaba en un proceso creativo familiar, me dijo: "aunque copien, los diseños siempre salen diferentes".

De esta forma, la distinción individual era la condición de existencia de los cánones familiares, de la "tradición" que resultaba del consenso entre familias y de la sociabilidad de los seris. Como Anne Christine Taylor advirtió para la pintura corporal y facial entre los achuar de Ecuador en la década de 1980, también en este caso: "no se trata[ba] de una diferencia dentro del marco de una identificación, sino más bien de una identificación exacerbada dentro del marco de una diferenciación" (Taylor 2003: 320). Estos vínculos también eran constitutivos de la manufactura de la cestería. Durante la recolección de torote o haat las mujeres elegían y cortaban las ramas del arbusto que sería la materia prima de los canastos; al quemar las ramas de torote y procesar las fibras intentaban particularizar su técnica mediante el uso de agua dulce o salada y de la calidad de las fibras por su grosor. Este hecho se reiteraba durante la producción de tinturas, del teñido de fibras y del tejido, procesos en los que dejaban como una impronta su marca personal. A manera de ejemplo, revisemos los procesos de cambio y de permanencia del uso de tinturas vegetales e industrializadas.

En 1985, Richard S. Felger y Mary B. Moser (1985: 94, 393, 396-398, $402,407)$ documentaron siete colorantes vegetales: tres tonos de rojo, dos negros y dos amarillos. Además del uso de anilinas con las que teñían las fibras de color negro introducido en los años sesenta (Felger y Moser 1985: 143), en mi registro documenté el proceso para elaborar el rojo denominado heepol (red-brown), el amarillo llamado xomeete y una mujer replicó por iniciativa propia el proceso conocido como haat ah hipool para elaborar un tono negro, a saber, se muelen las ramas de un arbusto que crece en las dunas de arena llamado en español "chamizo" (probablemente Atriplex canescens, A. linearis, A. polycarpa, cf (Felger y Moser 1985: 275-277), se coloca en un bote de metal oxidado con agua dulce y se dejan reposar dos semanas con fibras teñidas con heepol. ${ }^{7}$

Uno de los resultados de este registro fue que, de manera análoga a la expresada durante la manufactura de diseños o el procesamiento de las fibras, las tinturas y particularmente la variación de tonos fungían como marcas distintivas entre las tejedoras. Este fue el motivo por el cual se abandonó la técnica para producir colorantes negros mediante técnicas como el haat ah hipool. Inicialmente las mujeres argumentaron que este 
proceso de producción de tintura requería demasiado tiempo. No obstante, la preparación de tinturas rojas como el heepol implicaba una complejidad técnica similar. Ante esta reflexión, las mujeres seris comentaron que no utilizaban más el haat ah hipool por dos razones. Primero, porque su elaboración implicaba teñir las fibras en la casa de otra mujer, propietaria de un bote de metal lo suficientemente grande, hecho que limitaba su independencia e individualidad, ya que se producía un único tono de negro para todas las fibras. Segundo, porque, tal como ellas evidenciaron al mirar las fotografías de las canastas tejidas en la década de los veinte y treinta del siglo XX de la colección etnográfica del Arizona State Museum ${ }^{8}$ el tono logrado no era tan intenso ni tan "bonito" como el producido con las anilinas, en ocasiones eran pálidos o grisáceos.

Estos ejemplos muestran que la variabilidad individual era constitutiva de las técnicas textiles y de las técnicas de vinculación social de los seris, y no, como documentó la literatura revisada, una expresión de desgaste, corrupción o, en última instancia, de un vaciamiento semántico y cultural que atestiguaría la avasalladora inevitabilidad histórica del exterminio y de la integración al sistema económico, social y político del Estado mexicano, al que han sido sometidos los comcaac.

\section{Artefactos de historia}

Pensar en la variación individual desde las teorías y las prácticas de los seris fue fundamental para formular la analogía entre la cestería seri y el concepto de artefactos de historia postulado por Strathern.

Al mirar una foto de una canasta de la colección etnográfica del Museo Nacional de Antropología de la Ciudad de México, una mujer de El Desemboque dijo "esa canasta la tejió mi mamá", acto seguido me mostró una fotografía donde su madre la sostenía entre sus brazos. Este evento de identificación era espontáneo y recurrente. Al cuestionar a las mujeres cómo lograban reconocer a las tejedoras, señalaban las formas de los canastos, el tamaño y la forma del rollo, la técnica para procesar las fibras, los tonos de las tinturas de las fibras y los diseños; todas ellas, expresiones de la variación individual. Las canastas eran piezas únicas y, al mismo tiempo, eran objetosregistros que cada mujer había manufacturado-entablado desde su presente con el pasado; y que a su vez, proyectaba la "tradición" hacia el futuro autodefiniendo a los seris como una nación. Este fue el caso de una mujer que tejió una canasta con un diseño (cocömonjc u ondulado), inspirado en una fotografía tomada en 1951 en la Isla Tiburón. Ella indicó que su costo 
monetario sería elevado por su antigüedad. También Bertha Estrella, luego de apreciar la belleza de una foto de la colección etnográfica del Museo Nacional de Antropología, decidió tejer una canasta con un diseño similar. La finalidad era que la compráramos, estableciendo de esta forma lazos con su "tradición" y con nosotras (ver Figura 1).

Estos ejemplos etnográficos evidencian que la cestería y los diseños tejidos en ella vinculan los conceptos nativos de lo antiguo o de la "tradición" con su valor en el mercado de arte y que la relación con una mujer del pasado y con un comprador futuro son mutuas e indispensables, una es la condición de intensificación de la otra. En las canastas con diseños, literalmente se tejen lazos de temporalidad, una canasta del pasado no podría ser "tradicional" sin la que se ha tejido en el presente con el proyecto de venderla en el futuro. Simultáneamente, durante el proceso de manufactura se tejen lazos de parentesco y de ancestralidad, convirtiéndo cada cesto en un registro biográfico e histórico, ya que a partir de los vínculos que desde el presente se establecen con el pasado es posible recrear historias sobre las tejedoras y la forma de vida de otros seris no contemporáneos. Más aún, estos artefactos autocontienen distintos contextos que, al igual que los artefactos de historia de los que habla Strathern, sólo pueden ser elucidados durante el tejido y la circulación comercial, es decir, en un proceso "performático" de transmisión y de producción del conocimiento, del tiempo y de los lazos sociales.

Como analicé en otro sitio y tal como señaló Carlo Severi (2007) para las pictografías de la Biblia Dakota sioux y las producidas por algunos kiowa, cheyenne, arapaho, comanche y caddo que estuvieron en la prisión Fort Marion, Florida entre 1873 y 1875, los diseños seris expresan las formas en que se transmite y se crea la "tradición" y sus registros. Inclusive, es posible que, al igual que para los sabarl de Melanesia (Battaglia 1990), la memoria de los comcaac fuera una potencia productiva capaz de fijarse en los objetos.

Hasta este momento examiné la fricción que generó la obligación académica de construir un contexto histórico y las relaciones involucradas en la cestería seri. A manera de contraste, mostré que al ubicarnos como estudiosos de los contextos —-tales como la historia del Estado mexicano-, los canastos de rollo, los seris y nuestras propias producciones escritas terminan siendo un ejemplo y una justificación de la existencia de dicho marco de referencia. Siguiendo a Strathern, examiné la cestería manufacturada por las mujeres seris de El Desemboque como contenedora de su propio contexto y, por tanto, de su propia historia, si es que aún podemos continuar calificando de esta manera a la relación que estas personas entablan con la construcción del tiempo, de la memoria, de sus lazos de parentesco y del registro. 
Parafraseando a Strathern (2014b: 211), demostré que las mujeres seris no necesitan "explicar" la cestería o hacer referencia a eventos fuera de ella para elucidar los eventos que "contiene".

Pie de figura 1. Inspirada en una foto de la colección etnográfica del Museo Nacional de Antropología e Historia (a la izquierda), Bertha Estrella tejió una canasta que calificó como tradicional (a la derecha). Antes de proceder a la compra-venta, esta mujer seri colocó las fotografías sobre su mesa de trabajo y solicitó que tomara una fotografía. Para ejemplificar cómo este evento, autocontenido en dicha fotografía, fue sometida a nuestros marcos de referencia, sugiero a las lectoras y lectores consultar la edición de esta imagen en Martínez Ramírez (2016a, Figura 8-b), la cual, de acuerdo con los cánones estéticos de la revista fue una condición necesaria para su publicación. Foto de la autora.

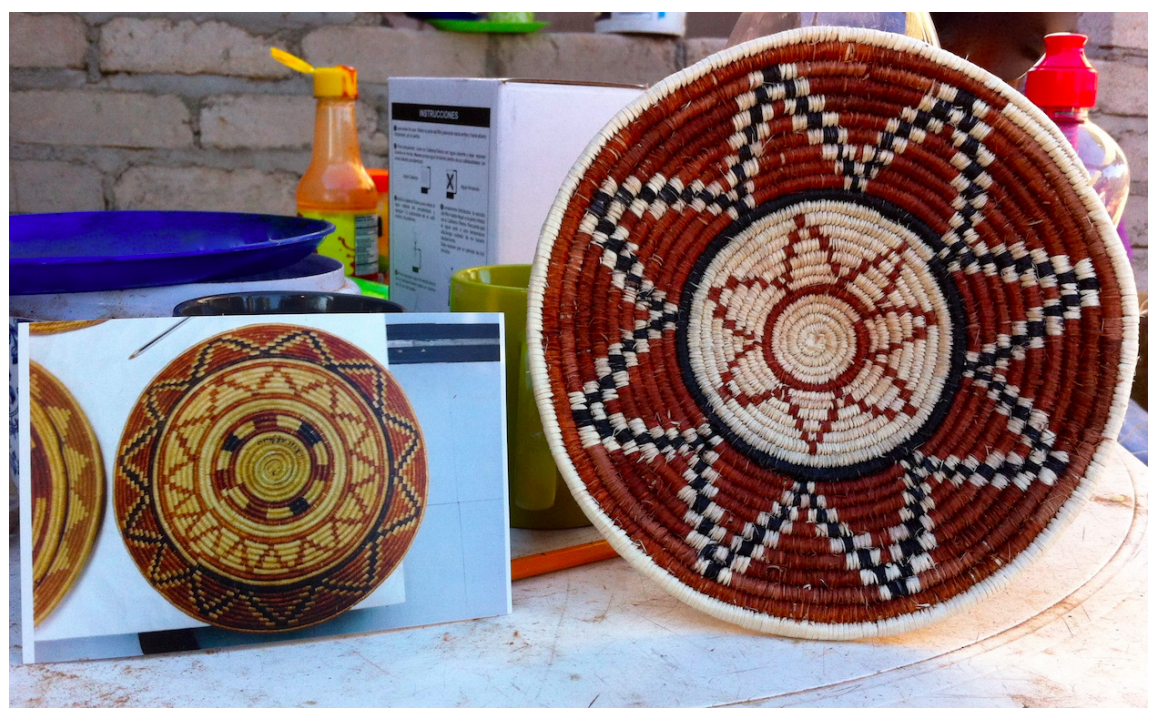

Aún así, persiste la sospecha de que a través de esta explicación he recaído en la paradoja anotada por Strathern al final del texto "Artefatos da historia: os eventos e a interpretação de imagens". Al tomar como dado el conocimiento de la socialidad de los seris he recaído en su referenciación y en su codificación. Y, como advertía esta autora: “La paradoja radica en que, al tomarlo como dado, ese tipo de conocimiento melanesio de la sociedad no será referenciado y codificado. Pero nosotros sólo conseguimos aprender esa dimensión por medio de nuestros procedimientos de referencia y codificación" (Strathern 2014b: 227, el resaltado es de la autora). En otros términos, intuyo que mi procedimiento expositivo y analítico (y aquí es donde reside la paradoja), definido por la traducción y por la explicación literal de una metáfora o la descripción de un objeto en palabras, implicó alterar el significado presentado. Dicho de manera llana, presiento que a lo largo de estas páginas solo he sustituido un contexto "histórico" (de tipo malinowskiano) por otro "nativo" (idel tipo frazeriano?). No obstante, la propuesta de Strathern no se reduce a esta sustitución. 
Al entablar una discusión con Marshall Sahlins sobre la tensión entre el evento y la estructura, Strathern indicó que al considerar las interpretaciones de las personas como "su historia" o como una "etnohistoria" solo reconstruimos, mediante nuevos contextos, los códigos de referencia nativos. La alternativa sería buscar las imágenes que los artefactos y los eventos se esfuerzan en transmitir, con el fin de reconocer que las visiones del tiempo implicadas son apenas formas de "explicar" o de "explicitar" la naturaleza de las cosas, por ejemplo, de los eventos como hechos históricos o de los eventos como efectos de una improvisación única (Strathern 2014b: 214-215). No se trata, pues, de privilegiar una interpretación (en este caso nativa) en detrimento de otra (contextos históricos) para presentar algo que simplemente sería el artefacto o el evento (Strathern 2014b: 221).

Aquello que propone esta antropóloga es más radical: modificar, de una manera que resulte irreconocible, nuestras ideas sobre el contexto, el evento, el suceso, el tiempo, la historia. La meta sería dislocar nuestras analogías y explicaciones sustituyendo una imagen por otra o un performance por otro hasta los límites del lenguaje. Sin duda, esto se parece mucho al final de la disciplina antropológica tal y como la conocemos (Viveiros de Castro 2009 y 2014), proyecto que encuentro altamente emocionante y estimulante por su potencia para descolonizar al colonizador.

Por este motivo y con base en este límite analítico propongo lo siguiente: El registro de las fricciones provocadas por el encuentro entre la fabricación de un contexto histórico y las historias indígenas no se reduce a reportar dos versiones de una historia — que tendría nuevamente como marco de referencia la historia del Estado nación-, ni mucho menos a documentar dos historias - cada una con su propio contexto-. Las historias indígenas no son la cara de la otra moneda, ni mucho menos dos monedas distintas, porque análogo a la sonaja del chamán que resulta más cercana a un acelerador de partículas que al juguete de un bebé (Viveiros de Castro 2008), eso que denomino historias indígenas es otra cosa; por ejemplo, un acto de guerra para los tupinambá en Amazonas (Carneiro da Cunha y Viveiros de Castro 1985) o un proceso de olvido para los achuar de Ecuador (Taylor 1993).

La temporalidad imbricada en la manufactura de la cestería seri, por ejemplo, sería más parecida a las ondas gravitatorias primordiales que, condensadas en el registro de un pulso durante su paso por la tierra, resumirían los eventos o la historia total del universo. De la misma forma, el conocimiento para producirla sería similar a las teorías físicas sobre el tiempo y el espacio que han funcionado como premisa para construir la tecnología a través de la cual ha sido posible registrar dicho pulso. Estos artefactos de historia no requieren de una traducción para ser elucidados. 
En ambos casos autocontienen eventos y contextos que es factible conocer a través de las técnicas y de la tecnología que ha sido fabricada con base en el conocimiento de dichos eventos y contextos. No estoy sugiriendo que la historia indígena sea equivalente a algunas cosmologías de las ciencias físicas modernas (aunque en los dos casos los legos no comprendan su complejidad y a pesar de que parezcan ininteligibles, ambas tienen efectos muy concretos sobre las realidades vividas). Por el contrario, lo que trato de insinuar es que, si las ondas gravitatorias y las teorías físicas fuesen un artefacto de historia, no serían un mito de origen cosmogónico, sino fibras tejidas en un canasto por las manos de una mujer. Con el fin de experimentar las consecuencias de esta propuesta, en lo que resta del artículo ensayo algunas reflexiones -en construcción- sobre lo que denomino registros amerindios del conflicto.

\section{Historias autocontenidas}

Entre 2014 y 2018 impartí una serie de cursos en el Posgrado en Historia del Arte y el Posgrado en Estudios Mesoamericanos de la Universidad Nacional Autónoma de México que me llevaron de la antropología del arte hasta la historia amerindia. Una tarea de estas asignaturas fue construir los eslabones que, a manera de una cadena que ha sido tejida sin un diseño previo, articularon una secuencia de preguntas formuladas al interior del aula sobre los registros amerindios del conflicto. Una mañana tomé un taxi hacia la universidad y el conductor, un hombre de aproximadamente cincuenta años, preguntó por mi profesión y por mi interés en la enseñanza de la historia indígena. Le expliqué brevemente, quizá durante dos minutos, en qué consistía aquello que llamábamos registros amerindios del conflicto y que sin duda encontramos, como una recurrencia, en las fuentes bibliográficas que revisábamos en clase. Luego de escuchar con atención, tuvimos la siguiente conversación:

—iAh! Ya sé de qué está hablando— dijo el conductor —. Es como lo del dolor de dientes, por eso nos duelen.

— ¿Cómo? - Indagué.

- Sí, eso que dicen, que por la conquista sufrimos mucho de la boca, como de las muelas del juicio.

—iAh! Claro. 
Este breve diálogo autocontiene todas las características compartidas por los registros amerindios del conflicto. Primero, requieren de una comprensión y de una experimentación compartida, en este caso del dolor que caracteriza la presencia de las muelas del juicio y de otros dientes. Segundo, están incorporados — sea en el cuerpo, en una imagen o en un evento- - Tercero, el dolor individual y la violencia colectiva a la que remiten los definen. Finalmente, su explicación es autoevidente, autocontenida y tendencialmente performática.

Por ello, para traducir este diálogo, es necesario reconocer que el artefacto de historia o el registro del conflicto (por el momento omitiré su carácter amerindio) es el dolor potencial o vivenciado en la boca y su contexto de elucidación deriva del dolor mismo. Por tanto, el diálogo es artificial. Aún así, esta conversación no precisó de la explicación que requieren las lectoras y lectores de este artículo.

El dolor al que refería el conductor del taxi se remonta al siglo XVI y a la historia nacional mexicana que ha sido revisitada críticamente por Navarrete Linares (2019). ${ }^{9}$ El dolor de la boca condensa la violencia del mito de mestizaje primigenio elaborado por el Estado mexicano y nutrido por diversos académicos. En este relato "los españoles conquistaron México", provocando una combinación indisoluble y condenando a los derrotados a un trauma histórico que se expresa en la vida social, cultural, espiritual y política del gran grueso de la población mexicana; y que, desde la perspectiva de quienes se identifican con los criollos hasta el presente (ibéricos que nunca se mestizaron), justifica la estructura racial, económica y cualquier tipo de discriminación y exclusión en el México contemporáneo. La relevancia y la cercanía de estos eventos, a decir de este historiador, "se debe a que muchos sentimos que aquellos sucesos determinan todavía quienes somos y cómo nos relacionamos" (Navarrete Linares 2019: 15).

De esta forma, es sabido que la mezcla entre españoles e indígenas tuvo efectos negativos sobre la descendencia, tales como tener una boca pequeña y dientes muy grandes. Este desafortunado desencuentro de rasgos fenotípicos, causantes de terribles dolores y de procedimientos médicos definidos como "medievales", también resume la violencia que implicó ese mestizaje mítico, esto es, la violación sexual de miles de mujeres que serían nuestras madres originarias. El dispositivo para incorporar esta historia —independientemente de su contenido mítico y nacionalista_-, como el conductor confirmó al reconocerlo con facilidad, es análogo a un registro del conflicto amerindio. Y, como podrán advertir las lectoras y los lectores esto no es un tipo de "etnohistoria", sino que es otra cosa. 
Como señalé, la formulación de la noción que he denominado registro del conflicto amerindio fue producto de una revisión de bibliografía antropológica dedicada a temas como el cuerpo, soportes visuales, así como danzas y rituales. En dicha bibliografía, el dolor, la violencia y el conflicto eran recurrentes. Por tanto, su centralidad no fue producto de una búsqueda previamente diseñada, sino de lo reportado en la etnografía. Con el objetivo de mostrar la pertinencia de dicha noción y de reflexionar sobre algunas de sus consecuencias analíticas, a manera de ejemplo reseño dos referencias fundamentales: La memoria ritual. Locura e imagen del blanco en una tradición chamánica amerindia de Carlo Severi (1996) y Ch'ulel: una etnografía de las almas tzeltales (1996) de Pedro Pitarch.

Con base en el trabajo de campo que realizó entre 1977 y 1984, Severi documentó y analizó, entre los cunas que habitaban la Comarca de San Blas en Panamá, "el nacimiento, el uso ritual y la persistencia de la memoria de una imagen del blanco [que] enc[erraba] la memoria de un largo conflicto" (Severi 1996: 13). La costa de San Blas fue una de las primeras tierras continentales conocidas por los ibéricos en el siglo XVI y hasta la década de 1990 aún gozaba de cierta autonomía. Panamá declaró su independencia en 1903 y el territorio cuna quedó dividido entre Colombia y esta nueva república. Sin embargo, para 1920 los pueblos amerindios se sublevan y proclaman la república de Tule y, desde entonces y hasta la visita de Severi, los cuna vivían entre una autonomía vigilada y de conflicto con el gobierno de Panamá. Mulatupu, una pequeña isla del archipiélago de San Blas, donde este antropólogo realizó su etnografía, está situada cerca de la selva del Darién. En aquella época, los cuna vivían en islas de tierra coralina, desprovistas de agua dulce que las mujeres buscaban en el río cotidianamente, practicaban la agricultura y la caza, y en menor medida la pesca.

Desde un abordaje inédito para la época que procuraba diluir la ilusión de las sociedades sin escritura y, por tanto, "sin historia", este antropólogo se preguntó: "¿qué retiene y qué borra la memoria de una sociedad? ¿Cómo se conserva en el tiempo ese saber compartido que llamamos tradición?". Para atender a estos cuestionamientos, estudió los procedimientos del chamanismo cuna para transmitir la memoria con el fin de mostrar que "la imagen de una América ajena a la historia [...] depende más de las opciones metodológicas y de los criterios dominantes en la literatura americanista, que de la realidad" (Severi 1996: 20) —demostración que constituyó gran parte de la obra posterior de este autor (Severi 2010 [2004], 2007). 
Entre toda la riqueza de este volumen, la idea que nutrió la noción de registro amerindio del conflicto fue el vínculo entre "la representación de la experiencia individual (captada en general a través del dolor, la incertidumbre, la desorientación) y una forma particular de la memoria histórica, ligada al contexto ritual" (Severi 1996: 23) del canto cuna Nia-ikala o Canto del Demonio. No me detendré a describir la etiología ni la patología de lo que Severi traduce como una "concepción indígena de la locura". ${ }^{10}$

Me interesa destacar el examen de la transmisión del conocimiento chamánico articulado con este padecimiento y con su cura mediante el secreto. Para los cuna, ya sea por un conocimiento innato o un conocimiento transmitido por vía de la jerarquía chamánica, "hay una lógica de secreto que vincula el alma a la palabra y ésta al conocimiento de lo invisible" (Severi 1996: 98). Sin duda, para quienes hemos sido educados bajo el marco de referencia de la escritura y de la historia kantiana, considerar que el secreto es el fundamento de una memoria compartida resulta contraintuitivo. ${ }^{11}$ No obstante, para los cuna la enfermedad y el dolor - una forma de sentir sin ver (Severi 1996: 123) — estaban asociados a un secreto.

Por este motivo, Severi centró su reflexión en la actividad del chamán, particularmente en la enunciación, cuya función secreta era "construir una tierra incógnita poblada de símbolos y modificada a medida que la historia [iba] provocando perturbaciones y conflictos" (Severi 1996: 120). Como resultado, este autor indicó que "la idea de la metamorfosis, de la constante compenetración de unos mundos diferentes [y] el estilo narrativo de esos textos [chamánicos]" (Severi 1996: 121), fundamentado en el concepto cuna pinyemai (el constante cambio de aspecto), surgían del dilema provocado entre la explicación y la experiencia del dolor y del sufrimiento. Por ello, "viajar", esquema de la curación cuna, "significa comprender las modificaciones del mundo a través de un modelo del dolor físico o del trastorno de la percepción que provoca la locura" (Severi 1996: 123).

El blanco (uaka o "espíritu maligno"), el extranjero, era uno de los espíritus patogénicos con mayor presencia en la época en la que Severi realizó su etnografía. Y pese a sus intentos por diluir la ilusión de los pueblos sin historia, este autor redujo la relación entre la enfermedad, el procedimiento chamánico que documentó y el proceso de colonización del territorio que confinó forzadamente a los cuna a una "ilusoria posesión de un rehén blanco" que "parec[ía] la triste operación mágica de un pueblo realmente asediado y al mismo tiempo trágicamente encerrado en su propia hostilidad" (Severi 1996: 108). Más aún, con la intención de no condenar a sus interlocutores a la ingenuidad, Severi arremete afirmando que "los indios 
saben perfectamente que los protagonistas de esas batallas [en sus relatos sobre los espíritus] eran hombres, y no misteriosas presencias animales" (Severi 1996: 109).

En otro texto, este autor vuelve a reflexionar sobre la forma paradójica (capaz de olvidar y de registrar) de la memoria social inscrita en soportes visuales de los cuna denominados nuchugana que, utilizados durante la ejecución de los cantos, representaban a los "espíritus auxiliares" (nelegan). Suma a su análisis componentes de la teoría freudiana, algunas ideas de Aby Warburg y concluye que "como muchas otras sociedades amerindias, la tradición chamánica kuna ha elegido la dimensión supernatural (con sus relaciones de la representación del sufrimiento) para representar crisis sociales y traumas colectivos" (Severi 2000: 147). Coincido con Carlos Fausto cuando afirma para los kaagúa o kaiová, un subgrupo guaraní, que este tipo de hechos no son representaciones en el sentido dramático, y sumaría que tampoco son representaciones supernaturales que no pueden explicarse por las leyes de la naturaleza o que superan sus límites, en el sentido epistemológico. Por ejemplo, entre los kaiová del siglo XVII, utilizar los objetos o los hábitos de los monjes ritualmente no era una representación (en los términos planteados arriba), sino una transformación para apropiarse del poder de los otros, tal como utilizar máscaras o las pieles del jaguar (Fausto 2005: 394).

Por ello, pese a su relevante aportación para comprender los vínculos entre el dolor encarnado y la memoria ritual, Severi explicó la historia de los cuna como un ejemplo de su marco de referencia: la colonización de los blancos. Este también ha sido el caso de algunos textos de Pedro Pitarch (2004) dedicados a la crítica del zapatismo en México. Aún así, la etnografía temprana de este autor entre los tzeltales de Cancúc en México es una importante aportación al tema que nos ocupa. Las visitas de campo de este antropólogo fueron realizadas entre 1989 y 1990, en aquel momento Cancúc era un municipio que contaba con 22000 hablantes de maya-tzeltal. En las contrastantes diferencias de altitud del territorio, oscilantes entre 2200 y $600 \mathrm{msnm}$, se desarrollaban intensas actividades agrícolas que incluían maíz, frijol y café.

Al elaborar, como el título de su libro lo declara, una etnografía de las almas, Pitarch (1996: 9) exploró las nociones de sincretismo cultural, memoria histórica, los fundamentos de la identidad colectiva y el papel de la comunidad. En el cuarto capítulo de este volumen, este autor expone claramente cómo para los cancuqueros, lo otro o el otro es parte del sí mismo: "El extraño está dentro de uno mismo" (Pitarch 1996: 107). 
Si bien, esta idea es estructural en la etnografía realizada por Severi entre los cuna, Pitarch advierte que en Cancúc esta tensión es fundamental para entender a los tzeltales y su historia.

Las almas o voluntades del corazón (chu'ulel, lab, el ave del corazón) se caracterizan por poseer rasgos "castellanos" (Pitarch 1996: 107, 123). Estas almas residen en el corazón que se contrapone a la cabeza y al cuerpo indígena. Por tal motivo, "en Cancúc no se nace indígena; la adquisición de la identidad social [es] un prolongado, continuo y difícil proceso de hacerse por encima de las identidades naturales previas" (Pitarch 1996: 125). La distribución de estas almas es diferencial: "unos indígenas poseen hasta trece lab y otros uno solo; en unos casos son lab 'fuertes' y en otros 'débiles' [...]. Por consiguiente, unas personas están más afectadas de alteridad que otras, o lo están de modo diferente" (Pitarch 1996: 133).

De acuerdo con Pitarch, sus interlocutores declararon que sabían pocas narraciones - cuentos, mitos, leyendas, etc.—o "historias". El motivo, según sus propias palabras, era el siguiente: "nos preocupamos únicamente por la actividad diaria, por el trabajo, por la conservación de la vida; además a diferencia de los 'castellanos', los cancuqueros carecemos de la escritura y no hemos podido registrar lo que ocurrió en el pasado" (Pitarch 1996: 14, el resaltado es mío). A pesar de esto, algunos lab que residían en los corazones de estos cancuqueros eran una suerte de "almas históricas" (Pitarch 1996: 135). Denominadas $a k^{\prime}$ chamen (los "dadores de enfermedad"), el común denominador de estos lab era la facultad del lenguaje. Aves del corazón europeas, ganado, herramientas metálicas, sacerdotes, escribanos o la escritura, ganaderos, música cristiana, el cultivo del café e incluso dentistas de la UNAM constituían este bestiario de almas tzeltales.

A través de la revisión de sus rasgos corporales, de su vestimenta y potencialidades, cada uno de estos lab condensaba procesos históricos complejos, como la presencia de frailes dominicos entre el siglo XVI y finales del XIX, o la ocupación territorial por la economía del café durante el siglo XX. La región central de Chiapas, donde se ubica Cancúc, fue ocupada por los ibéricos desde 1528, convirtiendo a las poblaciones amerindias en tributarias y en albos de las epidemias. Pocos años después, en 1545, arribaron los frailes dominicos y el primer obispo de Chiapas, fray Bartolomé de las Casas. Fue hasta 1855, con la consolidación del poder liberal y las medidas anticlericales que la documentación parroquial refleja la rápida y la progresiva erosión de la autoridad de los curas de Cancúc. Este también era el caso de la escritura, la cual remitía al poder o a la autoridad de los funcionarios del Estado. Por ejemplo, durante el Censo General de la nación en 1980, las personas escondían a sus hijos por el temor que provocaba la 
inscripción del nombre en un libro, una constante en los encuentros entre indígenas y castellanos (Pitarch 1996: 155).

"La conexión entre esos lab 'dadores de enfermedad' con la historia de Cancúc —dirá Pitarch (1996: 164) — es patente". Más allá de esta corroboración, este autor destaca que los lab encarnan técnicas de fuerza (institucionales, políticas, culturales, tecnológicas) dirigidas a transformar la vida indígena. En palabras del etnógrafo: "Es un tipo de memoria que no parece tan interesada en resaltar las formas de dominio violento, desnudo, como esas otras no tan fáciles de percibir dirigidas a reeducar a la persona, a rehacer su concepto, a alterar el entorno cotidiano sobre el que ésta se mantiene" (Pitarch 1996: 164). O, como afirmaban sus interlocutores tzeltales, este no era propiamente un registro de lo que sucedió en el pasado.

Esta conclusión fue fundamental para formular la noción de registro del conflicto amerindio, pues la reeducación de la que habla Pitarch nuevamente remite a un registro del dolor individual provocado por eventos definidos por la violencia. Por tanto, "esta interiorización de la historia no es el resultado de una lenta y acumulativa 'sedimentación' temporal de eventos progresivos, sino un procedimiento de plegado - concepto que el autor desarrolla posteriormente para explicar el pensamiento indígena (Pitarch 2013) - mediante el cual [...] lo otro es interiorizado" (Pitarch 1996: 165166). Y agregaría como una especificación que, aquello que es interiorizado es la violencia del otro y sus procedimientos de ejecución sobre cuerpos concretos y personas particulares.

Estas reflexiones fueron un parteaguas para acercarme al trabajo de Tristan Platt (2001) y de otros autores en los Andes (Abercrombie 1993, Wachtell 1996, Fernández Juárez 2006). En "El feto agresivo. Parto, formación de la persona y mito-historia en los Andes", Platt describe el proceso de gestación, las técnicas de parto y el tratamiento del neonato llevadas a cabo para producir nuevas personas en Macha, una comunidad quechua hablante de Potosí, ubicada en la región baja puna (aproximadamente $3800 \mathrm{msnm}$ ). En el siglo XVI, los macha eran el ayllu (comunidad social extensa con una descendencia común que trabajan colectivamente un territorio compartido) dominante en la federación aymara y la provincia inka de Qaraqara. Entre 1994 y 1995, período de las temporadas de campo de Platt, esta forma de organización se encontraba fracturada y marginada pero aún presente. Considerando que las relaciones con la economía mercantil se remontan al desarrollo de la minería de plata en el siglo XVI, este autor advirtió que la forma de vida de las personas con quienes trabajó eran "el fruto de un proceso secular de ajuste reflexivo, automodernización activa e intervención política" (Platt 2001: 130). 
Caracterizado por el dolor y la violencia incorporada en las mujeres, la gestación de cada neonato "replica[ba] la historia de la sociedad nativa andina" y definía sus ideas sobre su propia otredad, "como una población de perpetuos conversos andinos" (Platt 2001: 149). En cada gestación la mujer recibía un alma pagana, demoníaca y ancestral (supay) en su cuerpo. De ahí el riesgo latente de morir asesinada por el feto durante el embarazo y el parto. Posterior al alumbramiento, el recién nacido era cubierto con un útero paterno elaborado con telas. El objetivo era crear un nuevo cristiano que, en el fondo, resguardaba la reencarnación de un ancestro. Pese a la detallada etnografía presentada, Platt califica este proceso como un psicodrama mitohistórico inconsciente (Platt 2001: 150). El problema de su interpretación radica nuevamente en que ubica este fenómeno en un contexto histórico y social definido por sus propios parámetros de la realidad.

Y aquí es preciso volver al trabajo de Pitarch, porque la etiología y los procedimientos de curación narrados en Las almas tzeltales ejemplifican cómo el contexto y los eventos incorporados sólo son conocidos en el acto performático del diagnóstico y de la curación. Como señalé, al interior de los cancuqueros reside una diversidad de voluntades e intenciones que manifiestan sus deseos de manera autónoma. En consecuencia, los lab que producen enfermedades pertenecen a personas específicas que, no necesariamente, tuvieron la intención de provocarlas. En consecuencia, sólo a través del diagnóstico y de la curación, por tanto del dolor individual del cuerpo, es posible conocer la historia colectiva que está incorporada en aquel que provocó la enfermedad y en aquel que la padece.

Desde mi lectura, este sufrimiento individual no tiene como marco de referencia un contexto histórico que las personas de Cancúc conocerían previamente a la aparición de la enfermedad (manera bajo la cual nosotros solemos construir narrativas etnográficas). Por el contrario, los eventos encarnados en el padecimiento corporal sólo se conocen a través de su encarnación y manifestación. Dicho de otra manera, la historia sólo puede ser descrita como producto del dolor y del performance; de ahí, sugiero, la relevancia del secreto $y$, posiblemente, la evitación del registro que tiene como soporte la palabra. En este sentido, los cancuqueros, como los quechua hablantes del Potosí no reproducen y no replican la historia de la colonización como si fuese un autoengaño, una representación traumática o un psicodrama inconsciente, ya que dicha historia no precede a la enfermedad. Por el contrario, el dolor es la causa de la existencia de los eventos y de los hechos, y no su consecuencia. Por ello, en términos de Strathern, estos artefactos de historia no requieren un contexto elucidado, ellos son el contexto. 
Uno de los efectos de esta reflexión, como también señalaba Strathern (2014b: 215), es que estas visiones del tiempo, en este caso amerindias, sólo pueden ser entendidas como distintas formas de explicar o de explicitar la naturaleza de las cosas. Si, por una parte, nosotros tenemos hechos históricos, definidos como ocurrencias accidentales en la naturaleza, que requieren de un contexto para su comprensión, es decir, dar cuenta de sus relaciones con otros eventos de manera progresiva; por otra, y para los casos de Melanesia, los eventos experimentados como performances son conocidos por sus efectos y comprendidos por las formas que ocultan o revelan, es decir, como una sucesión de dislocamientos en los cuales las imágenes tienen la capacidad de evocar el pasado y el futuro simultáneamente como hechos únicos (Strathern 2014b: 215). Entonces, ¿qqué problemas análogos plantean los registros amerindios del conflicto?

Similar a lo que sucede en Melanesia, la temporalidad no es progresiva, sino performática tanto como podría ser un happening. Y al igual que para la cestería seri, para el caso de los cancuqueros y de los quechua hablantes, el pasado sólo existe por su relación con el presente y con su posible proyección al futuro. Si hiciéramos una traducción reversible, en el sentido otorgado por Wagner (1981), quizá nuestra experiencia más cercana podría ser la descripción que Svetlana Aleksiévich (2019 [2001]: 43) elaboró sobre la nueva temporalidad creada en Chernóbil, desde la cual "cada bieloruso es una especie de 'caja negra' viva que registra las informaciones para el futuro". Desde esta perspectiva, quizá no podríamos hablar más de una memoria indígena ni de técnicas mnemónicas, porque la relación temporal implicada imposibilita la experiencia del recuerdo o de la repetición de hechos históricos progresivos. El cáncer provocado por la radiación no es un recuerdo, ni una técnica de memoria, como he dicho sobre los registros del conflicto amerindio es otra cosa.

\section{Palabras finales: ¿Qué nos puede enseñar esto sobre la historia indígena?}

El objetivo de este artículo fue examinar las fricciones generadas por los encuentros y los desencuentros entre la construcción de un marco de referencia y las teorías y las prácticas de los comcaac sobre su cestería, con el fin de aportar reflexiones y cuestionamientos en torno a la escritura de la historia indígena contemporánea en México. Uno de los efectos del examen de dichas fricciones fue reconocer que, echando mano de las ficciones persuasivas que auto legitiman a la antropología, al sustituir un contexto artificial (histórico, social o cultural, e incluso estatal) por un contexto nativo 
recaía en una paradoja de reemplazo. Con el fin de procurar vías alternas a esta encrucijada, experimenté la noción de registro amerindio del conflicto. La meta, como señalaba Strathern, fue modificar radicalmente nuestras ideas de contexto, evento, suceso, tiempo e historia.

Como conclusión, propongo que si la apuesta consiste en: "vaciar nuestra noción de historia como ocurrencia natural o fortuita de eventos que presenta un problema para la estructura [y] hablar de las personas usando un evento así como se puede usar un cuchillo, o crear una ocasión así como ellos crean una máscara o demuestran su competencia personal para exponer las fases de un banquete de acuerdo con un protocolo social estricto" (Strathern 2014b: 228), entonces requerimos, como advirtió tempranamente Severi, de otras metodologías —en el sentido amplio de las condiciones y las técnicas de producción de conocimiento.

En esta línea de pensamiento, sugiero que la teoría etnográfica, cimentada en "un desconocido fundamental", en el sentido propuesto por Marcio Goldman (2003, 2016) e inspirado en las reflexiones de Stengers, podría arrojar luz a estas cuestiones metodológicas. Por ejemplo, para indagar cuál es el grado de verdad que estamos dispuestos a aceptar en el discurso nativo, para experimentar la vergüenza deleuziana ante la pretensión de definir la realidad de los otros, para reconocer lo frágil que son nuestras creencias sobre los otros, para renunciar a que nuestras categorías sean más reales que las de los otros. ${ }^{12}$ Este procedimiento metodológico, cuya premisa sería un no saber, posiblemente nos permitiría romper con aquello que Stanislaw Lem llamó "el mito del universalismo cognitivo" (Le Guin [2016] 2012: 11). El objetivo sería reconocernos humillados y vencidos por nuestra incomprensión ante un mundo tan otro. Mundos de los cuales, con nuestras herramientas, apenas podríamos describir sus mecanismos. Como si estuviésemos dentro de una máquina de escribir y fuésemos diminutos y tan solo pudiéramos entender el funcionamiento de los engranajes, de las palancas y de los resortes, pero reconocer que nunca sabremos quién escribía ni mucho menos qué era lo que escribía (Lem 2017 [1951]).

Si lo expuesto hasta este momento puede enseñarnos algo sobre la historia indígena es que explorar los límites de nuestra comprensión, tales como los contextos académicos o los promovidos por la imaginación estatal, nos permite reconocer nuestra incomprensión de los registros incorporados y performáticos que se niegan a las restricciones impuestas por nuestras ideas sobre la historia. Y, a partir de esta incomprensión, tal como proponía Stengers (2013: 5), podemos experimentar aquello que sentimos "cuando, durante un debate, un participante toma la palabra y presenta lo que está siendo debatido 'de una manera un poco diferente', provocando una pequeña pausa". 
Recebido em 03 de fevereiro de 2020

Aprovado em 27 de julho de 2020

María Isabel Martínez Ramírez es doctora en antropología e investigadora de tiempo completo en el Instituto de Investigaciones Históricas de la Universidad Nacional Autónoma de México. Sus intereses de investigación giran en torno al estudio de la historia contemporánea desde la mirada nativa y la coproducción de laboratorios de historia con poblaciones amerindias en el norte de México. https://orcid.org/0000-0001-9376-8681

Email: isabelmr@unam.mx

\section{Notas}

1 Investigación realizada gracias al Programa UNAM-PAPIIT IN404220. Una versión preeliminar de este artículo fue presentada en el Taller de Laboratorios de Historia Indígena. Agradezco los comentarios vertidos en ese espacio, así como a los(as) dictaminadores(as) de este artículo. Todas las traducciones a lo largo del texto son mías.

2 El material etnográfico presentado aquí fue tomado de Martínez Ramírez (2016a y 2016b).

3 A lo largo de este escrito me referiré a este poblado como El Desemboque.

4 Sugiero consultar el debate entablado por Aguilar Gil sobre este tema en México. "Lo lingüístico es político (Putsktu'u: Ja putsk jëts ja tu'u)", Tierra Adentro. Consultado en: https://www.tierraadentro.cultura.gob.mx/lo-linguistico-es-politicoputsktuu-ja-putsk-jets-ja-tuu-2/ e "Intervención de Yasnaya Aguilar, habla en Mixe, por el Año Internacional de las Lenguas Indígenas" en la Cámara de Diputados, 2019. Consultado en: https://www.youtube.com/watch?v=502lzaNur8c

5 La visita al MNA fue realizada el 10 de octubre de 2013. Agradezco el apoyo del Mtro. Leopoldo Trejo para su ejecución y a Sergio Torres, encargado del Acervo de Antropología, así como a la Dra. Carolyn O'Meara. De acuerdo con las fichas físicas, la mayoría de las piezas fueron ingresadas en la colección en 1978, 1985 y 1999. 
6 Agradezco a Steve Marlett y Cathy Moser Marlett la sugerencia para desarrollar este ejercicio y a Carolyn O'Meara por su asesoría lingüística durante el trabajo de campo. El procedimiento de levantamiento de datos consistió en una secuencia de preguntas y respuestas en Cimque Iitom en las que participaban una tejedora y una traductora. Mostraba las imágenes de la base de datos y procedíamos al cuestionario. Las entrevistas fueron transcritas en campo con Debora Perales, quien corregía mi escritura y acrecentaba datos sobre la cestería y los diseños.

7 La tintura roja se extrae por infusión en agua dulce o salada de la raíz del cósahui (Krameria grayi) (Moser y Marlett 2005: 371). El amarillo se procesa hirviendo las flores del arbusto Psorothamnus emoryi en agua dulce con las fibras de torote hasta lograr el color deseado.

8 Visita realizada del $1^{\circ}$ al 7 de noviembre. Agradezco el apoyo de la Dra. Carolyn O'Meara y de Diana D. Diettermore y Andrew T. Higgins, curadores de la colección etnográfica. Estas fotos fueron solicitadas por algunas tejedoras con el fin de contar con imágenes tradicionales para tejer sus diseños.

9 Sugiero consultar también https://www.noticonquista.unam.mx/. El proyecto de Noticonquista es una iniciativa de difusión histórica y multidisciplinaria de la UNAM, del Instituto de Investigaciones Históricas y de la Coordinación de Difusión Cultural. Encabezado por Federico Navarrete narra paso a paso, en tiempo real y desde diferentes puntos de vista, los acontecimientos sucedidos en el siglo XVI en el actual México.

10 Basta decir que ésta es categorizada por tres fases o estados: 1) purwa-saet (el-que-hace-como-el-viento) reconocible por desmayos, dolores de cabeza o temblor en las extremidades, embriaguez y deformación, tratable mediante la aplicación de hierbas medicinales; 2) niat-saet (el-que-hace-como-el nia), con síntomas como sueño patógeno, crisis agresiva y glosolalia animal y ante el cual se recita el canto nia-ikala; 3) tulekintaket o transformación total en "un cazador de ser humanos", un jaguar, y cuya solución es la muerte.

11 El secreto como basamento de la memoria también fue documentado por Taylor $(1993,2003)$ entre los shuar de Ecuador.

12 Cuestionamientos e ideas expuestas por Marcio Goldman en el curso sobre "Teoría etnográfica" impartido en el Posgrado en Estudios Mesoamericanos de la UNAM en septiembre de 2019. 


\section{Bibliografía}

ABERCROMBIE，Thomas.1993. "Caminos de la memoria en un cosmos colonizado. Poética de la bebida y la conciencia histórica en K'ulta". In: T. Saignes (ed.), Borrachera y memoria. La experiencia de lo sagrado en los Andes. La Paz, Hisbol / IFEA. pp. 139-185.

AGUILAR GIL, Yásnaya Elena. 2017. Ëëts, atom. Algunos apuntes sobre la identidad indígena, Revista de la Universidad de México, Septiembre 2017: 17-23.

AGUILAR ZELENY, Alejandro. 2013. "Con la memoria en las manos. La artesanía de los pueblos originarios de Sonora. Saaptim. Hilando los arbustos del desierto, la cestería y otros símbolos." Correo del maestro, 211: 47-55.

ALEKSIÉVICH, Svetlana. 2010 [2001]. Vozes de Tchernóbil. A história oral do desastre nuclear. São Paulo: Companhia das Letras.

BATTAGLIA, Deborah. 1990. On the Bones of the Serpent: Person, Memory, and Mortality in Sabaryl Island Society. Chicago: The University of Chicago Press.

BOWEN, Thomas. 1973. "Seri Basketry: A Comparative View". KIVA, 38(34):141-172. https://doi.org/10.1080/ 00231940.1973.11757778 1983. "Seri." In: A. Ortiz (ed.), Handbook of North American Indians. Washington: Smithsonian Institution. pp. 230-249.

CARNEIRO DA CUNHA, Manuela (org.). 1992. História dos índios no Brasil. São Paulo: Companhia das Letras.

2014 [2009]. "Cultura" e Cultura: conhecimentos tradicionais e direitos intelectuais". In: M. Carneiro da
Cunha (ed.), Cultura com aspas. São Paulo: Cosac-Naify. pp. 311-373.

CARNEIRO DA CUNHA, Manuela y VIVEIROS DE CASTRO, Eduardo. 1985. "Vingança e temporalidade: os Tupinamba". Jounal de la Sociéte des Américanistes, 71(1): 191-208. https://doi.org/10.3406/jsa.1985.2262

CUÉLLAR，Arturo José. 1980. La comunidad primitiva y las políticas de desarrollo. (El caso seri). México, D.F. : Universidad Nacional Autónoma de México.

FAUSTO, Carlos. 2005. "Se Deus fosse jaguar: canibalismo e cristianismo entre os Guarani (séculos XVIXX)". Mana, 11(2): 385-418. https://dx.doi.org/10.1590/S010493132005000200003

FELGER, Richard S., \& Mary B. MOSER. 1985. People of the desert and sea: Ethnobotany of the Seri Indians. Tucson: University of Arizona Press. FERNÁNDEZ JUÁREZ, Gerardo. 2006. "Kharisiris de Agosto en el altiplano Aymara de Bolivia". Chungara, 38 (1): 51-62. https://doi.org/10.4067/ s0717-73562006000100006

GARCÍA Y ALVA, Federico. 1905. Raza Seri. Sonora: Directorio del Estado de Sonora. Hermosillo. Consultado 3 de mayo de 2015, http://clima.dicym. uson.mx/archivo/misces/articulos/ expedicion1904.htm

GOLDMAN, Marcio. 2003. "Os tambores dos mortos e os tambores dos vivos. Etnografia, antropologia e política em Ilhéus, Bahia". Revista de Antropologia, 46(2): 423-444. https://doi.org/10.1590/s003477012003000200012

2016. "Cosmopolíticas, etnoontologías y otras epistemologías. La antropología como teoría etnográfica". 
Cuadernos de Antropología Social, 44: 27-35. https://doi.org/10.34096/ cas.i44.3578

GRIFFEN, William B. 1955. A Survey of Present Day Seri Culture. Master Dissertation, Centro de Estudios Universitarios of Mexico City College.

GUTIÉRREZ， Donaciano. 1999. "Cestería seri." In: E. Cortés Ruíz, \& C. Rodríguez Lazcano, Tejedores de la naturaleza en cinco regiones de México. México, D.F.: Instituto Nacional de Antropología e Historia. pp. 163-176.

HENARE, Amiria, Martin HOLBRAAD, \& Salli WASTELL. 2006. Thinking Through Things: Theorising Artefacts Ethnographically. London: Roudtledge. https://doi. org/10.4324/9780203088791

HOBSBAWN, Eric J. \& Terence RANGER (eds). 1983. "Introduction: In- venting Traditions". In: The Invention of the Tradition. Cambridge: Cambridge University Pres. pp. 1-14.

JOHNSON, Barbara. 1959. "Seri Indian Basketry". KIVA, 25(1): 10-13. https:// doi.org/10.1080/00231940.1959.11 757588

KANT, Immanuel. 1987 [1784]. "Ideas para una historia universal en clave cosmopolita". In: Ideas para una historia universal en clave cosmopolita y otros escritos sobre Filosofía de la Historia. Madrid: Editorial Tecnos. pp. 3-23.

LE GUIN, Ursula K. 2016 [2012]. "Presentación". In: A. Strugatski \& B. Strugatski (eds.), Stalker. Pícnic extraterrestre. Barcelona: Gigamesh Breve. pp. 9-11

LEACH, James. 2002. "Drum and voice: aesthetics and social process on the Rai Coast of Papua New Guinea". Journal of the Royal Anthropological Institute, 8(4): 713-734. https://doi. org/10.1111/1467-9655.00130
LEM， Stanislaw. 2017 [1951]. Astronautas. España: Impedimenta. LÓPEZ CABALLERO, Paula. 2017. Indígenas de la nación: etnografía histórica de la alteridad en México (Milpa Alta, siglos XVII-XXI). Ciudad de México: Fondo de Cultura Económica.

LÓPEZ CABALLERO, Paula L. \& ACEVEDO-RODRIGO, Adriana. 2018. Beyond Alterity: Destabilizing the Indigenous Other in Mexico. Tucson: University of Arizona Press. https://doi.org/10.1215/001821687573594

MALINOWSKI, Bronislaw. 1922. Argonauts of the Western Pacific. An Account of Native Enterprise and Adventure in the Archipelagoes of Melanesian New Guinea. London: Routledge \& Kegan Paul LTD.

MARTÍNEZ RAMÍREZ, María Isabel. 2016a. "Los diseños en la cestería seri: Ensayo sobre técnicas de vinculación social". Anales Del Instituto de Investigaciones Estéticas, 38: 135-170. https://doi.org/10.22201/ iie.18703062e.2016.109.2579

2016b. "Pensado a través de la cestería seri: permanencia, innovación y memoria". Itinerarios, 24: 215-239.

2020. Teoría etnográfica. Crónica por la antropología rarámuri. Ciudad de México: Instituto de Investigaciones Históricas-Instituto de Investigaciones Antropológicas, Universidad Nacional Autónoma de México.

MOSER, Edward. 1973. "Seri Basketry". KIVA, 38(3-4): 105-140. https://doi.or g/10.1080/00231940.1973.11757777

MOSER, Mary B. \& STEPHEN, Marlett A.. 2005. (coomps.). Comcaac quih yaza quih hant ihiip hac: Diccionario seri-español-inglés. Ciudad de México: Plaza y Valdés and Universidad de Sonora. 
NOLASCO, Margarita. 1967. Los seris, desierto y mar. México, D.F.: Anales del INAH.

NAVARRETE LINARES, Federico. 2015. Hacia otra historia de América. Nuevas miradas sobre el cambio cultural y las relaciones interétnicas. Ciudad de México: Universidad Nacional Autónoma de México. . 2016. "Entre a cosmopolítica e a cosmohistória: Tempos fabricados e deuses xamãs entre os astecas". Revista de Antropologia, 59(2): 86108. https://doi.org/10.11606/21790892.ra.2016.121934

. 2018. Historias mexicas. Ciudad de México: Editorial Turner, Instituto de Investigaciones Históricas, Universidad Nacional Autónoma de México.

2019. ¿Quién conquistó México? Ciudad de México: Debate.

O'MEARA, Carolyn. 2010. Seri Landscape Classification and Spatial Reference. Ph.D. Dissertation, University at Buffalo.

PÉREZ RUÍZ, Maya Lorena. 1993. Seris. México, D.F.: Instituto Nacional Indigenista. Colección Pueblos Indígenas de México.

PITARCH, Pedro. 1996. Ch'ulel: una etnografía de las almas tzeltales. México, D.F.: Fondo de Cultural Económica.

2004. "The Zapatistas and the art of ventriloquism". Journal of Human Rights, 3 (3): 291-312. https://doi.org/ 10.1080/1475483042000224851

2013. La cara oculta del pliegue: Antropología indígena. Ciudad de México: Artes de México.

PLATT, Tristan. 2001. "El feto agresivo. Parto, formación de la persona y mito-historia en los Andes". Estudios Atacameños, 22: 127-155. https://doi. org/10.3989/aeamer.2001.v58.i2.218
RAMÍREZ ZAVALA, Ana Luz. 2018. "La escuela rural en el territorio seri, 1920-1953". Relaciones. Estudios de historia y sociedad, 39 (154): 9-36. doi: 10.24901/rehs.v39i154.381

RENTERÍA, Rodrígo. 2007. Seris. Pueblos indígenas del México contemporáneo. Ciudad de México: Comisión Nacional de los Derechos de los pueblos Indígenas.

ROBLEDO HERNÁNDEZ, Gabriela. 1981. Los seris. México, D.F.: Instituto Nacional Indigenista.

SEVERI, Carlo.1996. La memoria ritual. Locura e imagen del blanco en una tradición chamánica amerindia. Quito: Biblioteca Abya-Laya. . 2000. "Cosmologia, crise e paradoxo: da imagem de homens e mulheres brancos na tradição Xamânica Kuna". Mana, 6(1): 121155. https://dx.doi.org/10.1590/ S0104-93132000000100005 2010 [2004]. El sendero y la voz. Una antropología de la memoria. Buenos Aires: Sb Editorial. . 2007. "Une forme mnémonique amérindienne. Pictographie et Parallélisme". In: Le Principe de la Chimère. Paris: Éd. Rue d'Ulm/ Musée du Quai Branly. pp. 89199. https://doi.org/10.4000/books. editionsulm.1039

SCHINDLER, Seth M. 1981. The material culture and technoeconomic view system of the Seri Indians: an experimental reconstruction. Ph.D. Dissertation. Illinois: Southern Illinois University.

SMITH, William. 1959. "Observations Regarding Seri Indian Basketry". KIVA, 25(1): 14-17. https://doi.org/10. 1080/00231940.1959.11757589

SPICER, Edward H. 1997 [1962]. "Seris." In: Cycles of Conquest. The Impact of Spain, Mexico, and the United States of the Indians of the Southwest, 
1533-1960. Tucson: The University of Arizona Press. pp. 105:117.

STENGERS, Isabelle. 2013. No tempo das catástrofes. Resistir à barbárie que se aproxima. São Paulo: CosacNaify. https://doi.org/10.1017/ CBO9781107415324.004

STRATHERN, Marilyn. 2014a. Fora de contexto: as ficções persuasivas da antropología, São Paulo: Terceiro Nome.

2014b. "Artefatos da história: os eventos e a interpretação de imagens". In: O efeito etnográfico. São Paulo: Cosac-Naify. pp. 211-230. TAYLOR, Anne-Christine. 1993. "Remembering to Forget: Identity and Memory Among the Jivaro". Man, 28 (4): 653-678. . 2003. "Les masques de la mémoire: essai sur la fonction des peintures corporelles jivaro". L'Homme, 165: 223-228.

VIVEIROS DE CASTRO, Eduardo. 2008. "O chocalho do xama é um acelerador de partículas". In: R. Sztutman (ed.), Encontros Eduardo Viveiros de Castro. Rio de Janeiro: Azogue. pp: 26-49. . 2009. Metafísicas caníbales: líneas de antropología postestructural. Buenos Aires: Katz. 2014. "Llevar a Serio... Contra el Infierno Metafísico de la Antropología. Entrevista realizada por A. Fujigaki Lares, Isabel Martínez, \& Denisse González". Anales de Antropología, 48(2): 219244. https://doi.org/10.1016/s01851225(14)70252-8

WAGNER, Roy. 1981. The Invention of Culture. Chicago \& London: The University of Chicago Press.

WACHTELL, Nathan. 1996. Deuses e vampiros: de Volta a Chipaya. São Paulo: Editora Universidade de São Paulo. 
HISTORIA "FUERA DE CONTEXTO": ARTEFACTOS DE HISTORIA ENTRE LOS COM CAAC DEL NORTE DE MÉXICO Y REGISTROS AM ERINDIOS DEL CONFLICTO

\section{Resumen}

Inspirada en Marilyn Strathern, el objetivo de este artículo es examinar las fricciones provocadas por el encuentro entre la obligación de construir un marco de referencia o contexto y las teorías pragmáticas de los comcaac o seris que residen en las costas del norte de México sobre determinados artefactos, como la cestería, que autocontendrían su contexto. La finalidad es experimentar los efectos analíticos de este desencuentro mediante la noción de registro amerindio del conflicto y contribuir en un debate más amplio sobre la escritura de la historia indígena contemporánea y la construcción de contextos que toman como marco de referencia al Estado nación.

Palabras Clave: Contexto, Historia indígena, Registro del conflicto, Comcaac.

\author{
HISTORY " OUT OF CONTEXT": \\ ARTIFACTS OF HISTORY AM ONG \\ THE COM CAAC OF NORTHERN \\ MEXICO AND AMERINDIAN \\ RECORDS OF CONFLICT
}

\section{Abstract}

Inspired by Marilyn Strathern, this article examines the conflict between the necessity of building a frame of reference or context, and the pragmatic theories of the Comcaac or Seris of the coasts of northern Mexico, in what pertains to certain artifacts, such as baskets, which carry their own specific context. My aim is to experiment with the analytical effects of this conflict through the notion of the Amerindian record of conflict, and to contribute to a broader debate on the writing of contemporary indigenous history and the construction of contexts that take the nation state as a frame of reference.

Keywords: Context, Indigenous history, Conflict record, Comcaac. 
HISTÓRIA “FORA DE CONTEXTO”:

ARTEFATOS DA HISTÓRIA ENTRE OS

COMCAAC DO NORTE DO MÉXICO

E OS REGISTROS AMERÍNDIOS DO

\section{CONFLITO}

\section{Resumo}

Inspirado por Marilyn Strathern, o objetivo deste artigo é examinar os atritos causados pelo encontro entre a obrigação de construir um quadro de referência ou contexto e as teorias pragmáticas da Comcaac ou Seris, que residem nas costas do norte do México, de certos artefatos, como a cestaria, que teriam seu próprio contexto. O objetivo é experimentar os efeitos analíticos dessa discordância através da noção de registro ameríndio do conflito e contribuir para um debate mais amplo sobre a escrita da história indígena contemporânea e a construção de contextos que tomam como referência o Estado-nação.

Palavras-Chave: Contexto, História indígena, Registro de conflito, Comcaac. 